\title{
BMJ Open Signs and symptoms preceding the diagnosis of Alzheimer's disease: a systematic scoping review of literature from 1937 to 2016
}

Fidelia Bature, ${ }^{1}$ Barbara-ann Guinn, ${ }^{1,2}$ Dong Pang, ${ }^{1}$ Yannis Pappas ${ }^{1}$

To cite: Bature F, Guinn B, Pang D, et al. Signs and symptoms preceding the diagnosis of Alzheimer's disease: a systematic scoping review of literature from 1937 to 2016. BMJ Open 2017;7:e015746. doi:10.1136/ bmjopen-2016-015746

- Prepublication history and additional material for this paper are available online. To view please visit the journal (http:// dx.doi.org/10.1136/bmjopen2016-015746)

Received 30 December 2016 Revised 6 June 2017 Accepted 7 June 2017

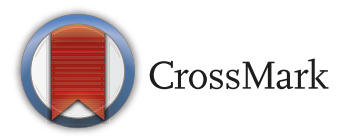

${ }^{1}$ Institute for Health Research, Putteridge Bury Campus, University of Bedfordshire, Putteridgebury, Luton, UK ${ }^{2}$ School of Life Sciences, The University of Hull, Hull, UK

Correspondence to

Dr Fidelia Bature;

fidelia.bature@study.beds.ac.uk

\section{ABSTRACT}

Objective Late diagnosis of Alzheimer's disease (AD) may be due to diagnostic uncertainties. We aimed to determine the sequence and timing of the appearance of established early signs and symptoms in people who are subsequently diagnosed with $A D$.

Methods We used systematic review methodology to investigate the existing literature. Articles were reviewed in May 2016, using the following databases: MEDLINE, PsycINF0, CINAHL, British Nursing Index, PubMed central and the Cochrane library, with no language restriction. Data from the included articles were extracted independently by two authors and quality assessment was undertaken with the quality assessment and diagnostic accuracy tool-2 (QUADAS tool-2 quality assessment tool). Results We found that depression and cognitive impairment were the first symptoms to appear in $98.5 \%$ and $99.1 \%$ of individuals in a study with late-onset $A D$ (LOAD) and $9 \%$ and $80 \%$, respectively, in early-onset $A D$ (EOAD). Memory loss presented early and was experienced 12 years before the clinically defined $A D$ dementia in the LOAD. However, the rapidly progressive late-onset $A D$ presented predominantly with 35 non-established focal symptoms and signs including myoclonus (75\%), disturbed gait $(66 \%)$ and rigidity. These were misdiagnosed as symptoms of Creutzfeldt-Jacob disease (CJD) in all the cases. The participant with the lowest mini-mental state examination score of 25 remained stable for 2 years, which is consistent with the score of the healthy family members.

Conclusions The findings of this review suggest that neurological and depressive behaviours are an early occurrence in EOAD with depressive and cognitive symptoms in the measure of semantic memory and conceptual formation in LOAD. Misdiagnosis of rapidly progressive $A D$ as CJD and the familial memory score can be confounding factors while establishing a diagnosis. However, the study was limited by the fact that each one of the findings was based on a single study.

\section{INTRODUCTION}

Alzheimer's disease (AD), the most common type of dementia, is a devastating disease with multiple presentations. While the disease is associated with old age, scientists ${ }^{12}$ have discovered that disease can develop at any
Strengths and limitations of this study

- The review indicates a paucity of data on the study objectives and heterogeneity in the timing of symptoms presentation in published studies.

- Comprehensive search strategy was used to identify articles for this review.

- This is the first review to identify the sequence and timing of the signs and symptoms in the early stage of Alzheimer's disease.

- Dearth of data, heterogeneity in methodology and findings made it impossible to draw a definite conclusion.

- Several other potential sources of heterogeneity like age, gender and education could not be investigated with the dearth of data

age and the reason for this is unclear. The disease could develop before the age of 65 years, known as early-onset AD (EOAD), which might be inherited or sporadic, or after the age of 65 years, known as late-onset $\mathrm{AD}$ (LOAD), that accounts for $90 \%$ of all $\mathrm{AD}$ cases. ${ }^{3}$ In the UK, a prevalence of 520000 has been reported in $2014^{4-6}$ with high individual, healthcare and financial burden. ${ }^{78}$ There are challenges in diagnosing the disease early, ${ }^{9-11}$ which can result to non-reversible symptoms progression, that lead to institutionalisation and high mortality rate among this group. ${ }^{12}$ There is also the emotional and physical burden to the caregivers ${ }^{13} 14$ as well as emotional, physical and financial burden to the healthcare system. ${ }^{15}$ Even though there is discourse in the meaning of the early diagnosis, here, it refers to the diagnosis at the lowest threshold of the disease or at the stage of mild cognitive impairment (MCI), with cluster of early signs and symptoms and the diagnosis of the pathology of the disease before dementia. This is because the disease has a preclinical stage with the clinical symptoms yet evident but with changes in the brain 
and the risk of progression unknown, intermediate stage with mild cognitive and functional changes and dementia due to $\mathrm{AD}$ stage with severe cognitive and functional decline.

Among the reasons for the late diagnosis is that the signs and symptoms, at the early stages of $\mathrm{AD}$, are sometimes not recognised and/or mistaken for signs of old age or symptoms of other conditions. ${ }^{516-18}$ The above may be partly due to the fact that the timing and sequence of the early presentation of signs and symptoms are not reported by current studies. ${ }^{19-21}$ Delaying onset of the disease by 5 years through early diagnosis and intervention could reduce the mortality rate of dementia (advanced stage of $\mathrm{AD)}$ by 30000 yearly. ${ }^{22}$

This review attempts to answer the following research question: how far back from diagnosis and in what sequence do the first symptoms that warrant an $\mathrm{AD}$ diagnosis appear? Further understanding of the timing and the sequence of the presentation of signs and symptoms may enable practitioners to offer timely intervention.

\section{METHODS}

\section{Types of studies}

All types of empirical studies were considered, excluding those of qualitative design.

\section{Participants}

Included participants were aged between 30 and 85 years and diagnosed with $\mathrm{AD}$.

\section{Settings}

Primary care, memory clinics or secondary care settings.

\section{Target condition}

$\mathrm{AD}$ and any subtypes were diagnosed with the following tools: (a) National Institute of Neurological and Communicative Disorders and Stroke AD and Related Disorders Association (NINCDS-ADRDA, UK), a commonly used criteria for $\mathrm{AD}$ dementia; (b) National Institute on Aging-Alzheimer's Association (USA), a more recent criteria that use biomarkers to support the diagnosis; (c) Diagnostic and Statistical Manual of the American Psychiatric Association (DSM-IV) ${ }^{23}$; and (d) DSM- $5 .^{24}$

\section{Outcomes}

The outcomes of this review included (i) the sequence of presentation of the signs and symptoms that are indicative of $\mathrm{AD}$ prior to diagnosis, ${ }^{20}$ (ii) the timing from the first reported symptom to diagnosis, ${ }^{20}$ (iii) the timing from MCI to diagnosed dementia stage, ${ }^{25}$ (iv) the timing of assessments leading up to a diagnosis of $\mathrm{AD}^{26}$ and (v) the timing from clinical presentations to case fatality or death. $^{27}$

\section{Index symptoms}

We used an index of early symptoms as a reference to ascertain the timing and sequence of events prior to disease presentation. The index is based on previous studies, ${ }^{28-32}$ which includes apathy, agitation, anxiety, anosognosia, aberrant motor behaviour, acalculia, alexia, anomia, disinhibition, depression, irritability, hallucination and olfactory disturbances and weight loss. ${ }^{28-32}$

\section{Exclusion criteria}

- Participants with other dementia or other neurological conditions;

- Inaccurate diagnostic criteria;

- Single index symptom;

- Late-stage $\mathrm{AD}$ (AD dementia); a set of symptoms including memory loss, difficulty in thinking, problem solving or language difficulties. ${ }^{33}$

\section{Search criteria for identification of studies}

We searched the literature via OvidSP MEDLINE (1950), PsycINFO (1887), British Nursing Index (1994), CINAHL (1937), PubMed central (2000) and the Cochrane register for diagnostic and intervention studies. We also used 'snowballing' and searched the references of relevant articles. Searches covered the period from 1937 to May 2016. No language or publication restrictions were applied. We used medical subject headings terms to standardise and improve the search; $\mathrm{AD}$ was the main term followed by the basic terms timing, onset and country, and the combination of terms. Details of the database search strategies are presented in online supplementary appendix 1.

\section{Data collection and analysis}

Assessment of methodological quality

The qualities of included studies were assessed using the QUADAS-2 tool, a methodological quality assessment tool used to assess diagnostic accuracy studies ${ }^{34}$ (table 1) and PRISMA checklist. The tool consists of 14 items that rates the risk of bias, source of variations (applicability and reporting of quality), with each item rated as 'yes', 'no' or 'unclear', tailored under four domains that includes: participants selection; index test (signs and symptoms interpretation), reference standard (diagnostic criteria that correctly classify the target condition) and flow and timing (time interval and intervention between index test and reference standard).

\section{RESULTS}

\section{Results of the search}

The process by which articles were identified, screened and selected for the review is described in figure 1. A total of 3528 articles were identified in the databases including 318 duplicates. Nine others were identified through hand searching, and 3179 were excluded based on the review of titles and abstract alone. The full-text versions of 40 were assessed for eligibility, 13 were initially included but 9 later excluded (reasons stated below). Four articles were finally included in the review. 


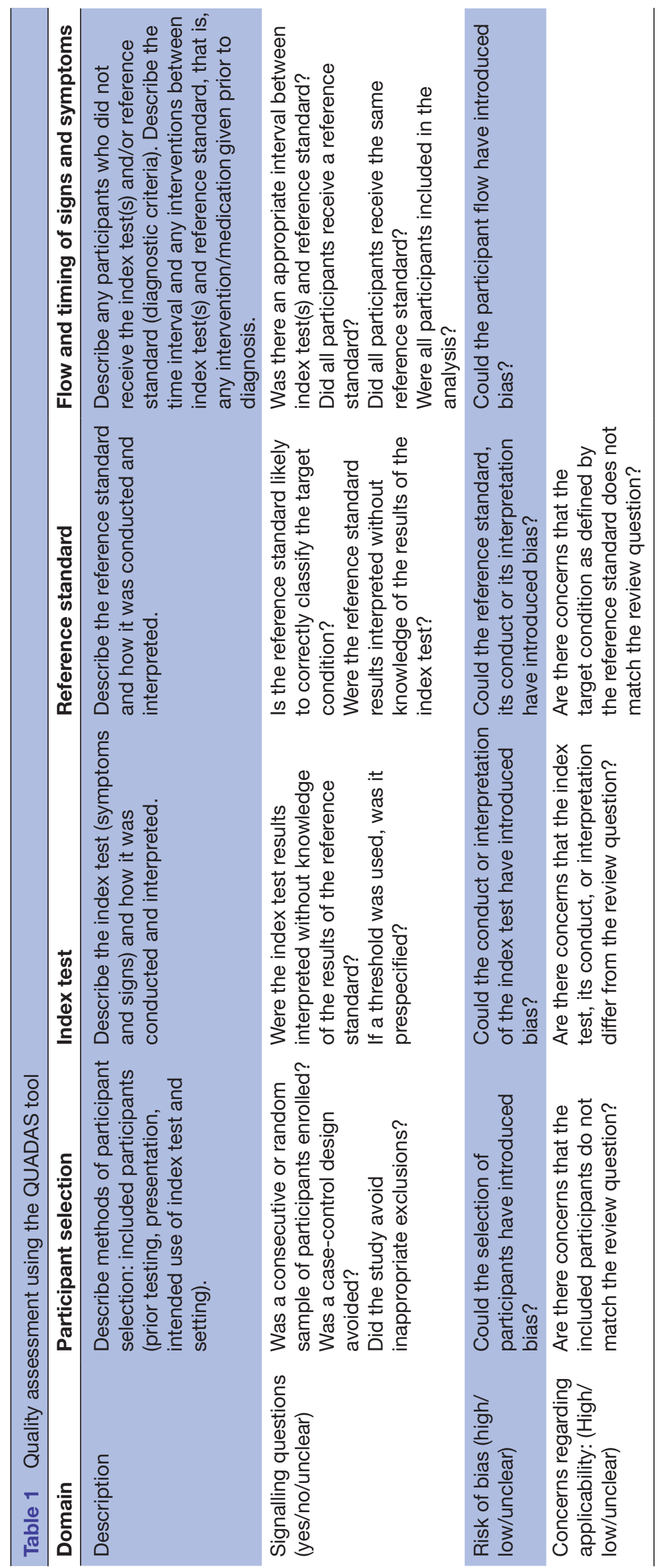




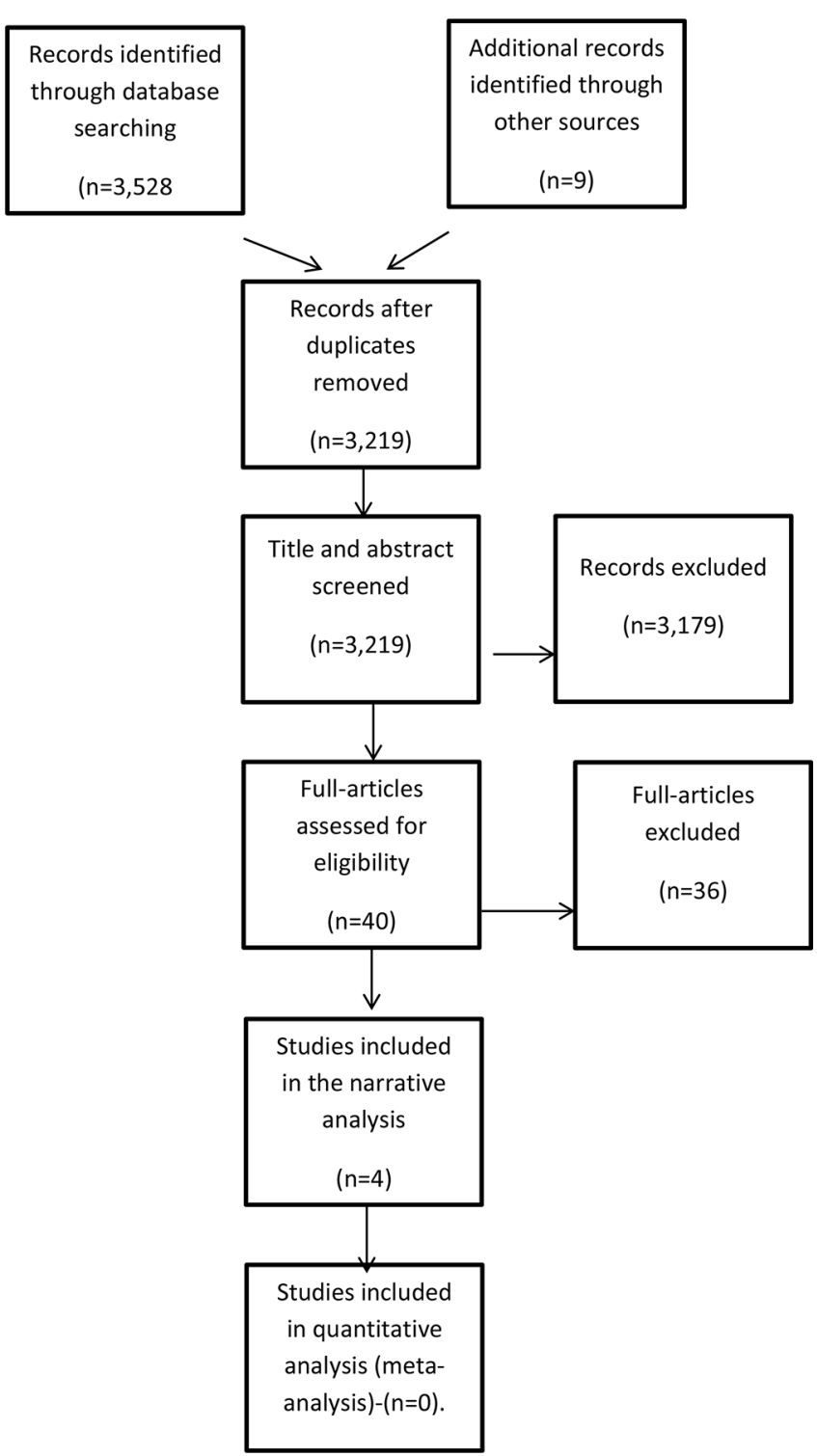

Figure 1 Flowchart indicating the process for the selection of studies. The flowchart indicates the articles identified through the search: those reviewed as title and abstract, those reviewed fully and the ones that met the inclusion criteria.

\section{Reasons for exclusion}

Although 13 studies were reviewed in full, 9 were excluded. The reasons for exclusion were: four studies were on unspecified dementia ${ }^{3035-37}$; one study was undertaken in a developing country ${ }^{38}$; another on caregiver's distress ${ }^{31}$; one study was on a single case ${ }^{22}$; one study had incomplete data, ${ }^{39}$ while another did not have a reference point for the diagnosis of $\mathrm{AD} .^{19}$

\section{Summary of findings}

Methodological quality of included studies

The methodological quality in each domain was assessed individually.

The QUADAS-2 scores for each domain (table 1) of the studies included in the review are shown in figures 2 and 3 . The reviewer included a nested case control with random sampling ${ }^{25}$ longitudinal follow-up of patients with MCI, ${ }^{20}$ longitudinal prospective study of individuals at risk of autosomal dominant familial $\mathrm{AD}(\mathrm{FAD})^{26}$ and a retrospective case study (postmortem) ${ }^{27}$ For the case studies, ${ }^{20} 2627$ the exclusion criteria were appropriate and sample selection was consecutive, which reduced the risk of selection bias. (table 2, figure 2)

The index test was not influenced by the reference standard in three studies. ${ }^{2025}{ }^{26}$ However, the index test domain was judged as having a high risk of bias in a study ${ }^{27}$ due to the fact that the index tests were interpreted based on the knowledge of the disease (postmortem). In the applicability concerns, the conduct and interpretation of the index symptoms were different from the review question in Fox et $a t^{26}$ and Schmidt $e t a l^{27}$ The Fox $e t a l^{26}$ study focused on the mean time from first assessment to the appearance of symptoms at reporting, while the study published by Schmidt $e t a l^{27}$ focused on identifying the median time span from clinical presentation of the disease to case fatality or death.

In the reference standard domain, all studies were undertaken using the diagnostic criteria for $\mathrm{AD}$, recognised internationally that could correctly classify the condition with masking in all. The Schmidt et al study $^{27}$ on rapidly progressive AD (RPAD) was undertaken postmortem, the gold standard for the diagnosis of $\mathrm{AD}$. However, none of the studies reported how the reference standard was operationalised or applied. They were assessed as being a low risk of concern about applicability.

In the flow and timing domain, there was an appropriate interval between the appearance of symptoms and signs and the reference standard. There was no mention of treatment in between the timings and all of the participants were diagnosed using the same reference standard. All participants were included in the analysis.

\section{Findings}

\section{Outcome I}

Of the 148 participants in the Devier et alstudy, ${ }^{20} 39$ (26\%) converted to $\mathrm{AD}$ and all of the converters were 55 years at baseline, indicating an EOAD. There were differences in the first symptom at presentation with memory decline reported as the first in $118(80 \%)$ of the cases, depressed mood in $13(9 \%)$, declined language in $6(4 \%)$, change in performance of higher order/cognitive activities in $4(3 \%)$, disorientation in $3(2 \%)$, personality changes and behavioural changes in $2(1 \%)$, with no group difference in symptoms reporting. Sequentially in the order of appearance of the signs and symptoms in all the participants, memory decline was the first followed by performance changes, changes in language, disorientation, personality changes, depressed mood, behavioural changes and psychosis, consecutively. However, for depression, reverse causality could be the case, as the history of depression with the first onset before the age of 60 years represents a risk of developing $\mathrm{AD}$ in later life ${ }^{40}$ and all cause dementia. ${ }^{41}$ 
Risk of Bias

Patient Selection

Index Test

Reference Standard
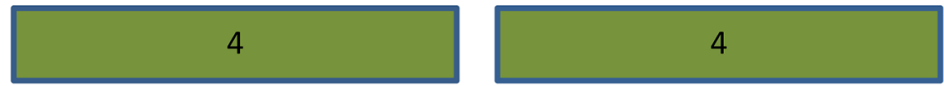

Flow and Timing

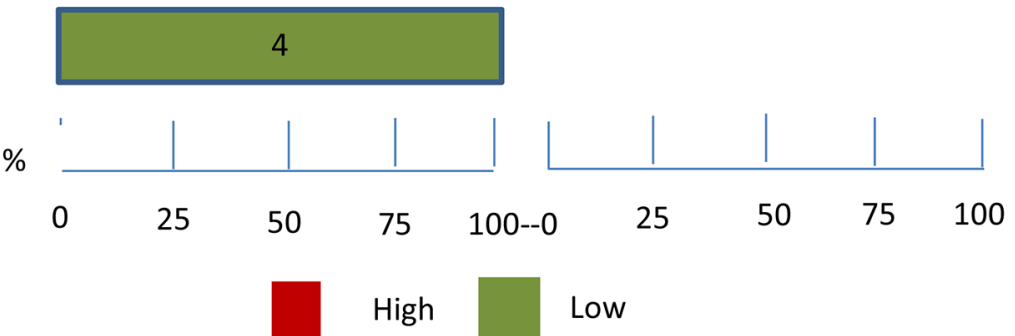

Applicability Concerns
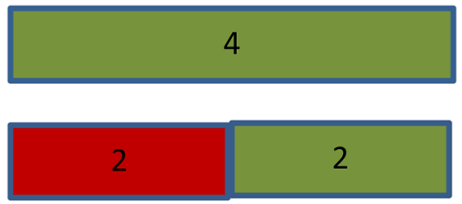

4

Figure 2 Graph representing the risk of bias and applicability concerns. Each domain is represented as a percentage across included studies for the review; the red colour indicates high risk, while green indicates low risk. However, none of the studies were given an unclear risk of bias and applicability concerns (QUADAS-2 tool).

\section{Outcome II}

Memory decline was experienced in 38.5 months before diagnosis, ${ }^{20}$ depressed mood in 37.4 months, performance in 36.8 months, personality changes in
32.5 months, behavioural changes in 31.1 months, language difficulties at 29.2 months, disorientation in 29.1 months and psychosis at 14.0 months prior to the diagnosis.

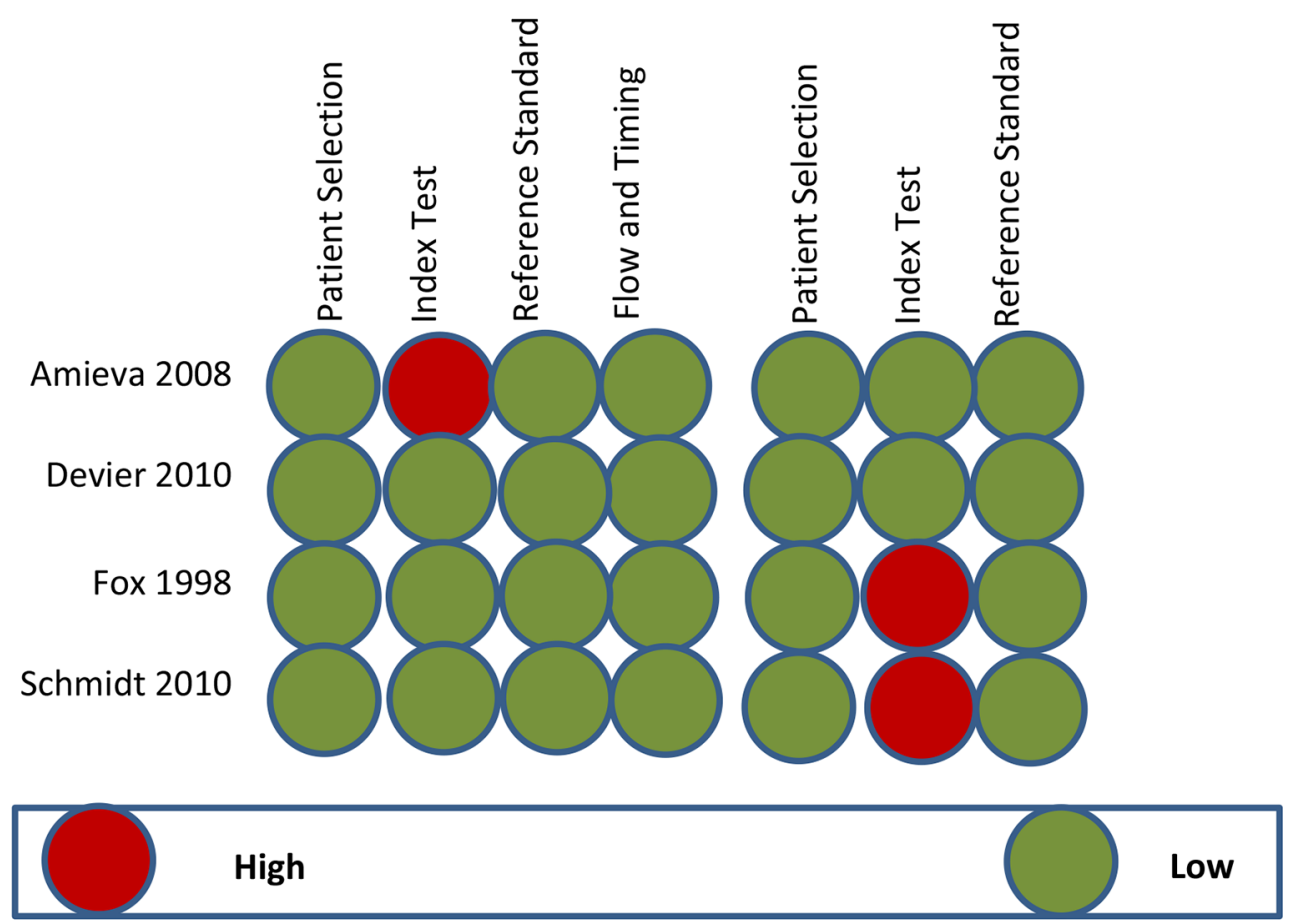

Figure 3 Summary of the risk of bias and applicability concerns. The reviewer's judgement on each domain for the included studies is shown with a high risk of bias and applicability concerns on index test for. ${ }^{32}$ 


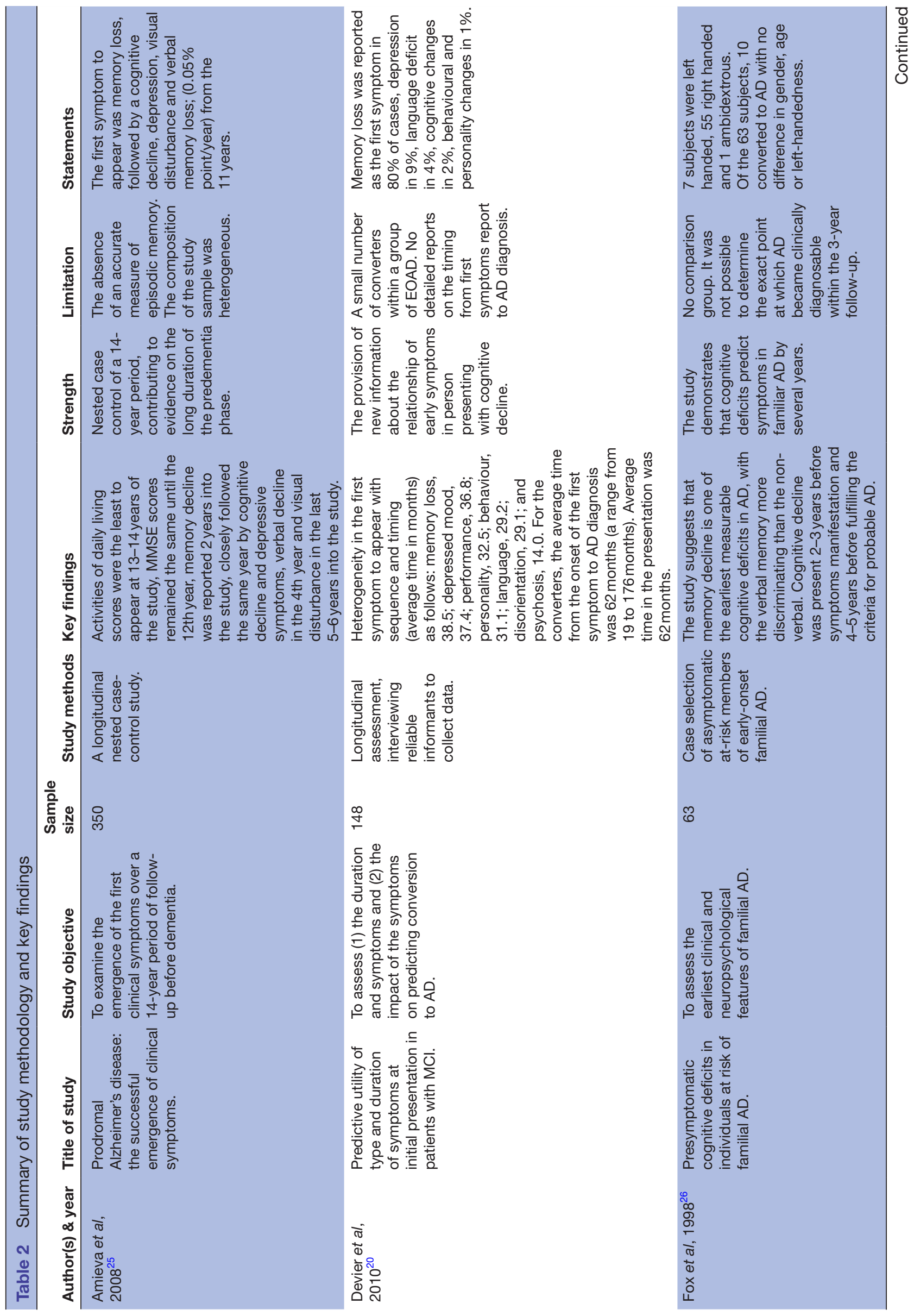


Outcome III

Amieva et $a l^{25}$ study reported cognitive decline 12 years before dementia in a measure of semantic memory and conceptual formation. Depressive symptoms appeared concomitantly with the cognitive decline and followed 2 years later with verbal memory decline. Two years later, visual disturbances were recorded and worsened until the dementia stage.

\section{Outcome IV}

Of the 63 subjects in the Fox $e t a l^{26}$ study of autosomal dominant $\mathrm{FAD}, 10$ converted to probably $\mathrm{AD}$ and the mean time $( \pm \mathrm{SD})$ from first assessment to the appearance of symptoms was 2.6 \pm 1.4 years. Episodic memory loss was the most common and noticed on average 6 months before symptomatic assessment. The study suggests that cognitive decline is present 2-3 years before symptoms and 4-5 years before individuals fulfil the criteria for probably $\mathrm{AD}$. There was no distinction in presentations with regards to age, gender and handedness. Verbal memory was superior to semantic memory in differentiating $\mathrm{AD}$ from normal ageing, with the lowest score in mini-mental state examination (MMSE) of 25 in a participant remaining stable for 2 years consistent with family members with the same score that remained healthy. This could help discriminate individuals at risk of conversion.

\section{Outcome V}

Thirty-five distinct neurological, psychiatric and autonomic symptoms and signs were identified in the Schmidt et $a l^{27}$ study. The sequence and timing in months (averagely 26.4) of the presentation of the signs and symptoms were as follows: disinhibition, 51.1; spasticity, 31.1; dysphagia, 21.6; akinetic mutism, 20.0; significant weight loss, 20.0; apraxia, 19.5; apathy, 17.0; sleep disorder, 16.0; delusions, 15.0; myoclonus, hallucinations, seizures, 13.0; impaired concentration, 4.5; depression, 4.0; and disorientation, 2.0, with others following thereafter. A third of RPAD experienced rapid weight loss and sleep disorder, indicating their significance in discriminating the disease from other dementias.

\section{Signs and symptoms}

A pooled estimate was not possible to be reported due to the differences in participants, symptoms and types of $\mathrm{AD}$, as well the scarcity of research that had reported on the sequence and timing of the early signs and symptoms. MCI was required at baseline in the Devier et al study, ${ }^{20}$ with memory complaints 6 months to 10 years prior to enrolment. The study began long before the Petersen ${ }^{42}$ MCI criteria definition. Prior to enrolment, memory loss was observed on average of 38.5; depressed mood, 37.4; performance, 36.8; personality, 32.1; behaviour deficits, 31.1; language deficits, 29.2; disorientation, 29.1 and psychosis, 14.0 months, before diagnosis.

For the 10 converters in the Fox et al study, ${ }^{26}$ the mean time $( \pm \mathrm{SD})$ from initial assessment to first symptomatic assessment was $3.1 \pm 1.5$ years (range $1-5$ years). The 
most common presentations were symptoms of very mild deficit in episodic memory. Two of the 10 subjects already had deficits in verbal memory and were the first to be symptomatic. Verbal memory deficit was observed 1-5 years during the symptomatic phase, indicating higher early sensitivity than the semantic memory and cognitive changes 2-3 years before the symptomatic phase. There was no difference observed between cases and non-converters in terms of age, gender, handedness or MMSE at initial assessment and symptomatic assessment.

In the Schmidt et $a l^{27}$ study, the median disease duration was 26.4 months and the median age at clinical onset was 73 years. The authors were unable to obtain a summary of the data from the onset of the symptoms to disease diagnosis.

All the studies were diagnosed with the NINCDSADRDA diagnostic criteria and symptoms measured with the neuropsychiatry inventory score.

\section{DISCUSSION}

Four studies met the inclusion criteria, which had heterogeneous objectives, diagnosis and participants. The four studies had a total of 593 people who were followed for conversion to $\mathrm{AD}$. All the studies assessed the timing of the signs and symptoms of $\mathrm{AD}$ prior to a formal diagnosis and/or case fatality, but with different participants and type of $\mathrm{AD}$.

Studies were assessed methodologically with the QUADAS-2 tool. Three of the included studies ${ }^{2026}$ validated their results via NINCDS-ADRDA and one study ${ }^{27}$ via postmortem examination.

Even though there were differences in timing, objectives, participants and type of $\mathrm{AD}$, the Fox $e t a l^{26}$ study on FAD identified a participant with an MMSE score of $25 / 30$, the lowest in the group, that remained the same for 2 years, similar to family members that remained well throughout. This supports the evidence that MMSE offers a reasonably good diagnosis and classification of $\mathrm{AD},{ }^{43}$ especially the accuracy of the MMSE baseline score. However, critics advised that the measurement should be interpreted with caution. ${ }^{44}{ }^{45}$ Furthermore, Schmidt et $a l^{27}$ discovered additional focal neurological symptoms consistent with Creutzfeldt-Jacob disease (CJD); AD was misdiagnosed as CJD until the postmortem study proved $\mathrm{AD}$ as the cause of the presentations. This finding is in line with Mega et $a l^{29}$ and Zahodne et $a l^{46}{ }^{46}$ who reported that there are measurable behavioural changes in $\mathrm{AD}$ and suggested that focal neurological symptoms are associated with poor prognosis. ${ }^{46}$

Memory disturbances remain the predominant differentiating factor between early $\mathrm{AD}$ and normal ageing in all of the studies. Verbal memory was more vulnerable than non-verbal in the early-onset familial $\mathrm{AD} .{ }^{26}$ The memory test for words indicated significant differences in scores, 1-5 years before becoming symptomatic, against the notion of semantic memory vulnerability.
Depressed symptoms appeared at the same time as cognitive symptoms, and each of these was the first symptom to appear in some individuals with LOAD. However, memory loss presented early and frequently in this group too. ${ }^{20} 40$ The rapidly progressive $\mathrm{LOAD}^{42}$ presented predominantly with myoclonus $(75 \%)$, disturbed gait $(66 \%)$ and rigidity $(50 \%)$. These symptoms were also early in the presentation process occurring before apathy. Neurological and depressive behavioural presentations are an early occurrence in EOAD.$^{20}$ This calls for further studies to identify the sequence and timing of the early signs and symptoms preceding the diagnosis, to aid the early detection and subsequent diagnosis of $\mathrm{AD}$.

The main limitation of this systematic review was the dearth of data and heterogeneity in methodology and findings in the included studies. Moreover, pooled estimate or statistical analysis for the signs and symptoms was not possible to be calculated and several other potential sources of heterogeneity like the age of onset, gender and education could not be investigated given the paucity of relevant data.

We excluded studies on individual symptoms and signs, as well as other types of dementia, where it was not possible to isolate AD. Further and rigorous research is needed to understand the timing and sequence of the appearance of the signs and symptoms that elude to $\mathrm{AD}$ prior to diagnosis, with the aim of supporting as early an $\mathrm{AD}$ diagnosis as possible.

\section{CONCLUSIONS}

There is a proposition of multiple definitions including MCI and subjective cognitive decline to capture the intermediate stage between ageing and mild cognitive changes, which is in line with the effort to diagnose $\mathrm{AD}$ early, by recognising the signs and symptoms as reliable predictive markers of the disease. ${ }^{46}$

There are currently insufficient published data on the sequence and timing of the early signs and symptoms of $\mathrm{AD}$. We advocate that more research should be undertaken in this area.

This review is important to general practitioners, researchers, health policymakers, the pharmaceutical industry and the public. The review is also of importance to neurologists and other practitioners dealing with dementing disorders.

Contributors $\mathrm{FB}$ and $\mathrm{BG}$ conceived the study and participated in the design and drafting of the manuscript. DP participated in the analysis and helped to draft the manuscript. YP suggested the design and participated in the selection of studies, design and drafting of the manuscript. FB developed the protocol of the study, conducted the analysis and drafted the manuscript. FB, DP, BG and YP read and approved the final manuscript for this publication.

Competing interests None declared.

Provenance and peer review Not commissioned; externally peer reviewed.

Data sharing statement № additional data are available.

Open Access This is an Open Access article distributed in accordance with the Creative Commons Attribution Non Commercial (CC BY-NC 4.0) license, which permits others to distribute, remix, adapt, build upon this work non-commercially, 
and license their derivative works on different terms, provided the original work is properly cited and the use is non-commercial. See: http://creativecommons.org/ licenses/by-nc/4.0/

(C) Article author(s) (or their employer(s) unless otherwise stated in the text of the article) 2017. All rights reserved. No commercial use is permitted unless otherwise expressly granted.

\section{REFERENCES}

1. Ridha BH, Barnes J, Bartlett JW, et al. Tracking atrophy progression in familial Alzheimer's disease: a serial MRI study. Lancet Neurol 2006;5:828-34

2. Williams SC. Alzheimer's disease: Mapping the brain's decline. Nature 2013;502:S84-S85.

3. Braskie MN, Jahanshad N, Stein JL, et al. Common Alzheimer's disease risk variant within the CLU gene affects white matter microstructure in young adults. J Neurosci 2011;31:6764-70.

4. Office for National Statistic, UK. Prevalence of Alzheimer's disease in the UK. (accessed May 6 2015).

5. Alz.co.uk. First World Health Organisation Ministerial Conference on Global Action against Alzheimer's Disease. www.alz.co.uk/./firstwho-ministerial-conference-on-global-action-againts.2015 (accessed Oct 10 2015).

6. Alzheimer's Society UK. Prevalence of Alzheimer's disease. https://www.alzheimers.org.uk/site/index.php?gclid=Cl-807W 2zs4CFRATGwodviYF5w.2015 (accessed Jan 20 2015).

7. Black SE, Gauthier S, Dalziel W, et al. Canadian Alzheimer's disease caregiver survey: baby-boomer caregivers and burden of care. Int J Geriatr Psychiatry 2010;25:807-13.

8. Takizawa C, Thompson PL, van Walsem A, et al. Epidemiological and economic burden of Alzheimer's disease: a systematic literature review of data across Europe and the United States of America. J Alzheimers Dis 2015;43:1271-84.

9. Health and Social Care Information Centre (HSCIC) Quality Outcomes Framework (QOF) Recorded Dementia Diagnoses: Provisional 2013/14 http://www.hscic.gov.uk/catalogue/PUB14624/ qual-outc-fram-rec-dem-diag-2013-2014-prov-rep.pdf.2014 (accessed 20 Feb 2015).

10. Rapp T. Patients' diagnosis decisions in Alzheimer's disease: the influence of family factors. Soc Sci Med 2014;118:9-16.

11. Alzheimer's Statistics. Alzheimer's Research UK. https://www. alzheimersresearchuk.org/statistics/late-diagnosis-of-Alzaheimerdisease.2015 (accessed Feb 07 2016).

12. Hyman BT, Phelps $\mathrm{CH}$, Beach TG, et al. National Institute on Aging-Alzheimer's Association guidelines for the neuropathologic assessment of Alzheimer's disease. Alzheimers Dement 2012;8:1-13.

13. Zarit SH, Todd PA, Zarit JM. Subjective burden of husbands and wives as caregivers: a longitudinal study. Gerontologist 1986;26:260-6.

14. Chiao CY, Wu HS, Hsiao CY. Caregiver burden for informal caregivers of patients with dementia: A systematic review. Int Nurs Rev 2015;62:340-50

15. Albers G, Van den Block L, Vander Stichele R. The burden of caring for people with dementia at the end of life in nursing homes: a postdeath study among nursing staff. Int $J$ Older People Nurs 2014;9:106-17.

16. Ording AG, Sørensen HT. Concepts of comorbidities, multiple morbidities, complications, and their clinical epidemiologic analogs. Clin Epidemiol 2013;5:199-203.

17. Jones RW, Romeo R, Trigg R, et al. Dependence in Alzheimer's disease and service use costs, quality of life, and caregiver burden: the DADE study. Alzheimers Dement 2015;11:280-90.

18. Kada S. Knowledge of Alzheimer's Disease among Norwegian undergraduate health and social care students: a survey study. Educ Gerontol 2015;41:428-39.

19. Palmer K, Bäckman L, Winblad B, et al. Early symptoms and signs of cognitive deficits might not always be detectable in persons who develop Alzheimer's disease. Int Psychogeriatr 2008;20:252-8.

20. Devier DJ, Villemarette-Pittman N, Brown P, et al. Predictive utility of type and duration of symptoms at initial presentation in patients with mild cognitive impairment. Dement Geriatr Cogn Disord 2010;30:238-44.

21. Shea YF, Chu LW, Chan AO, et al. Delayed diagnosis of an old Chinese woman with familial Alzheimer's disease. J Formos Med Assoc 2015;114:1020-1.

22. Dementia 2014 Report Statistics-Alzheimer's Society. https://www. alzheimers.org.uk/statistics (accessed 20 Mar 2015).
23. American Psychiatric Association A, American Psychiatric Association. Diagnostic and statistical manual of mental disorders. 1980.. http://dsm.psychiatryonline.org/doi/book/.

24. Freedman $\mathrm{R}$, Lewis DA, Michels $\mathrm{R}$, et al. The initial field trials of DSM-5: new blooms and old thorns. Am J Psychiatry 2013;170:1-5.

25. Amieva H, Le Goff M, Millet X, et al. Prodromal Alzheimer's disease: successive emergence of the clinical symptoms. Ann Neurol 2008;64:492-8.

26. Fox NC, Warrington EK, Seiffer AL, et al. Presymptomatic cognitive deficits in individuals at risk of familial Alzheimer's disease. A longitudinal prospective study. Brain 1998;121:1631-9.

27. Schmidt C, Redyk K, Meissner B, et al. Clinical features of rapidly progressive Alzheimer's disease. Dement Geriatr Cogn Disord 2010;29:371-8.

28. Oppenheim G. The earliest signs of Alzheimer's disease. J Geriatr Psychiatry Neurol 1994;7:116-20.

29. Mega MS, Cummings JL, Fiorello T, et al. The spectrum of behavioral changes in Alzheimer's disease. Neurology 1996;46:130-5.

30. Kang SJ, Jeong $\mathrm{Y}$, Lee $\mathrm{BH}$, et al. How early are initial symptoms recognized in Korean patients with Alzheimer's disease? Int J Geriatr Psychiatry 2004;19:699-700.

31. Craig D, Mirakhur A, Hart DJ, et al. A cross-sectional study of neuropsychiatric symptoms in 435 patients with Alzheimer's disease. Am J Geriatr Psychiatry 2005;13:460-8.

32. Ringman JM, Liang LJ, Zhou Y, et al. Early behavioural changes in familial Alzheimer's disease in the Dominantly Inherited Alzheimer Network. Brain 2015;138:1036-45.

33. Alzheimer's Association. 2015 Alzheimer's disease facts and figures. Alzheimers Dement 2015;11:332-84.

34. Whiting PF, Rutjes AW, Westwood ME, et al. QUADAS-2: a revised tool for the quality assessment of diagnostic accuracy studies. Ann Intern Med 2011;155:529-36.

35. Yoon Y-J, Kim E-J, Hong CH. Comparison of behavioral and psychological symptoms between early and late onset alzheimer's disease according to the progression of dementia. Dementia and Neurocognitive Disorders 2014;13:89-93.

36. Masters MC, Morris JC, Roe CM. Non-cognitive symptoms of early Alzheimer disease: A longitudinal analysis. Neurology 2015;10.

37. Di lulio F, Palmer K, Blundo C, et al. Occurrence of neuropsychiatric symptoms and psychiatric disorders in mild Alzheimer's disease and mild cognitive impairment subtypes. Int Psychogeriatr 2010;22:629-40.

38 Lopera F, Ardilla A, Martínez A, et al. Clinical features of early-onset Alzheimer disease in a large kindred with an E280A presenilin-1 mutation. JAMA 1997;277:793-9.

39. Jost BC, Grossberg GT. The evolution of psychiatric symptoms in Alzheimer's disease: a natural history study. J Am Geriatr Soc 1996;44:1078-81.

40. Geerlings MI, Schoevers RA, Beekman AT, et al. Depression and risk of cognitive decline and Alzheimer's disease. Results of two prospective community-based studies in The Netherlands. $\mathrm{Br} J$ Psychiatry 2000;176:568-75.

41. Diniz BS, Butters MA, Albert SM, et al. Late-life depression and risk of vascular dementia and Alzheimer's disease: systematic review and meta-analysis of community-based cohort studies. Br J Psychiatry 2013;202:329-35.

42. Petersen RC. Mild cognitive impairment as a diagnostic entity. $J$ Intern Med 2004;256:183-94.

43. Roalf DR, Moberg PJ, Xie SX, et al. Comparative accuracies of two common screening instruments for classification of Alzheimer's disease, mild cognitive impairment, and healthy aging. Alzheimers Dement 2013;9:529-37.

44. Votruba KL, Persad C, Giordani B. Cognitive deficits in healthy elderly population with "normal" scores on the Mini-Mental State Examination. J Geriatr Psychiatry Neurol 2016;29:126-32.

45. Arevalo-Rodriguez I, Smailagic N, Roque i Figuls M, et al. MiniMental State Examination (MMSE) for the detection of Alzheimer's disease and other dementias in people with mild cognitive impairment (MCl). The Cochrane Library 2015.

46. Zahodne LB, Ornstein K, Cosentino S, et al. Longitudinal relationships between Alzheimer disease progression and psychosis, depressed mood, and agitation/aggression. Am J Geriatr Psychiatry 2015;23:130-40

47. Flicker C, Ferris SH, Reisberg B. Mild cognitive impairment in the elderly: predictors of dementia. Neurology 1991;41:1006-9.

48. Stephan BC, Hunter S, Harris D, et al. The neuropathological profile of mild cognitive impairment $(\mathrm{MCl})$ : a systematic review. $\mathrm{Mol}$ Psychiatry 2012;17:1056-76. 